\title{
Aprotinin, but not $\varepsilon$-aminocaproic acid and tranexamic acid, exerts neuroprotection against excitotoxic injury in an in vitro neuronal cell culture model
}

\author{
Zhaohui Lu, MD, ${ }^{\mathrm{a}, \mathrm{c}}$ Ludmila Korotcova, MD, ${ }^{\mathrm{a}, \mathrm{b}}$ Akira Murata, MD, ${ }^{\mathrm{a}, \mathrm{b}}$ Nobuyuki Ishibashi, MD, ${ }^{\mathrm{a}, \mathrm{b}}$ and \\ Richard A. Jonas, MD
}

Objective: Lack of availability of aprotinin has resulted in increased clinical use of the alternative antifibrino-
lytic agents, $\varepsilon$-aminocaproic acid (EACA) and tranexamic acid (TXA), which are known to be associated with an
increased risk of seizures. In contrast, aprotinin has previously been demonstrated to be neuroprotective through
suppression of excitotoxicity-mediated neuronal degeneration via the extracellular plasminogen/plasmin sys-
tem. This study compares the effect of antifibrinolytic agents on neuronal and mixed glial/neuronal cell cultures.

\begin{abstract}
Methods: Mixed cortical cultures containing neuronal and glial cells were prepared from fetal mice and plated on a layer of confluent astrocytes from postnatal pups. A primary neuronal culture was obtained from the same gestational stage and plated in multiwall vessels. Slowly triggered excitotoxicity was induced by 24-hour exposure to $12.5 \mathrm{mM} \mathrm{N}$-methyl-D-aspartate (NMDA). Apoptotic neuronal cell death was induced by exposure of primary neural cultures to 24 hours of serum deprivation.

Results: Compared with NMDA alone, no significant changes in cell death were observed for any dose of TXA or EACA in mixed cultures. Conversely, a clinical dose of aprotinin significantly reduced cell death by $-31 \%$ on average. Aprotinin reduced apoptotic neuronal cell death from $75 \%$ to $37.3 \%$, and to $34.1 \%$ at concentrations of 100 and $200 \mathrm{kIU} / \mathrm{mL}$, respectively, and significantly decreased neuronal nuclear damage. These concentrations of aprotinin significantly inhibited caspase 9 and 3/7 activations; $250 \mathrm{kIU} / \mathrm{mL}$ aprotinin exerted maximal protection on primary cortical neurons.
\end{abstract}

Conclusions: In contrast to aprotinin, EACA and TXA exert no protective effect against excitotoxic neuronal injury that can occur during cardiac surgery. (J Thorac Cardiovasc Surg 2014;147:1939-45)

Low-flow cardiopulmonary bypass and deep hypothermic circulatory arrest are used to facilitate pediatric cardiac surgery although they carry a risk of ischemic brain damage. One mechanism of ischemic neuronal cell death is glutamatergic excitotoxcity. ${ }^{1}$ Initially, an ischemic insult impairs glutamate transport at the postsynaptic level resulting in high extracellular levels of glutamate $^{1,2}$ resulting in excessive calcium influx and eventually leading to neuronal cell death. ${ }^{1}$

Studies of excitotoxicity-mediated neuronal degeneration have identified the extracellular plasminogen/plasmin system as an important aggravating element, for example,

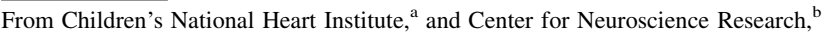
Children's National Medical Center, Washington, DC; and Department of Thoracic and Cardiovascular Surgery, ${ }^{\mathrm{c}}$ Shanghai Children's Medical Center, Shanghai, China

This study was funded by grant NIH R01HL060922 and grant R01HL104173 to R.A. Jonas.

Disclosures: Authors have nothing to disclose with regard to commercial support. N.I. and R.A.J. are joint senior authors.

Received for publication June 25, 2013; revisions received Aug 29, 2013; accepted for publication Sept 24, 2013; available ahead of print Nov 18, 2013.

Address for reprints: Richard A. Jonas, MD, Children's National Medical Center, 111 Michigan Ave, NW, Washington, DC, 20010-2970 (E-mail: rjonas@cnmc.org). $0022-5223 / \$ 36.00$

Copyright (C) 2014 by The American Association for Thoracic Surgery

http://dx.doi.org/10.1016/j.jtcvs.2013.09.054
}

through activation of intrinsic tissue-plasminogen activator. ${ }^{3,4}$ Aprotinin, which is used as an antifibrinolytic agent during cardiac surgery, inhibits plasminogen activation. We previously demonstrated that aprotinin has neuroprotective effects against glutamatergic excitotoxicity. ${ }^{5}$ It also protects endothelial function in the brain. ${ }^{6}$ Lysine analogs such as $\varepsilon$-aminocaproic acid (EACA) and tranexamic acid (TXA) block the binding of plasminogen to fibrin and plasminogen activation and transformation to plasmin. ${ }^{7}$ The lysine analogs, therefore, also have the potential to provide neuroprotection through their inhibition of plasminogen activation.

In the present study, a neuronal cell culture model was used to examine whether antifibrinolytic lysine analogs are also neuroprotective against glutamatergic excitotoxicity. The antiapoptotic effects of aprotinin were then assessed. The mechanisms underlying the neuroprotective effects of aprotinin were studied and the optimal dose for clinical application during cardiac surgery was investigated.

\section{METHODS \\ Primary Cortical Neuron Cultures \\ Primary cortical neuron cultures containing less than $5 \%$ astrocytes were obtained from fetal mice at 13 to 15 days' gestation (Charles River, Germantown, Md). Dissociated cortical cells in plating medium of media}




$$
\begin{aligned}
& \text { Abbreviations and Acronyms } \\
& \text { ANOVA }=\text { analysis of variance } \\
& \text { DIV }=\text { days in vitro } \\
& \text { DMEM }=\text { Dulbecco's modified Eagle's medium } \\
& \text { EACA }=\varepsilon \text {-aminocaproic acid } \\
& \text { FITC }=\text { fluorescein isothiocyanate } \\
& \text { GABA }_{\mathrm{A}}=\gamma \text {-aminobutyric acid type A } \\
& \text { LDH }=\text { lactate dehydrogenase } \\
& \text { MS }=\text { media stock } \\
& \text { MTT }=3 \text {-(4,5-dimethylthiazol-2-yl)-2, } \\
& \text { NMDA }=N \text {-methyl-D-aspartate } \\
& \text { RLU }=\text { relative light units } \\
& \text { SD }=\text { serum deprivation } \\
& \text { TXA }=\text { tranexamic acid }
\end{aligned}
$$

stock (MS; Dulbecco's modified Eagle's medium [DMEM] with $25 \mathrm{mM}$ glucose; Sigma, St. Louis, Mo) supplemented with 5\% fetal bovine serum (Gibco, Carlsbad, Calif), 5\% horse serum (Gibco, Carlsbad, Calif) and 2 $\mathrm{mM}$ glutamine (Sigma, St. Louis, Mo) were plated in 24-well plates coated with poly-D-lysine $(0.1 \mathrm{mg} / \mathrm{dL}$; Invitrogen, Carlsbad, Calif) and laminin $(0.02 \mathrm{mg} / \mathrm{mL}$; Invitrogen, Carlsbad, Calif). After 3 days in vitro (DIV), nonneuronal cell division was halted by exposure to $10 \mu \mathrm{M}$ cytosine arabinoside (Ara-C; Sigma, St. Louis, Mo). There was no further exchange of medium except the addition of DMEM for evaporation. All cultures were kept at $37^{\circ} \mathrm{C}$ in a humidified $5 \% \mathrm{CO}_{2}$ incubator. Cultures were used after 7 DIV for serum deprivation (SD). All experiments were performed in compliance with the National Institutes for Health Guide for the Care and Use of Laboratory Animals. The study was approved by the Institutional Animal Care and Use Committee of the Children's National Medical Center.

\section{Glial Cell Cultures}

Glial cell cultures were prepared from postnatal mice at 1 to 3 days old (Swiss Webster mice; Charles River, Germantown, Md). Dissociated cortical cells were plated in 24-well plates previously coated with polyD-lysine using a plating medium of MS supplemented with $10 \%$ horse serum, $10 \%$ fetal bovine serum (Gibco, Carlsbad, Calif), and $2 \mathrm{mmol} / \mathrm{L}$ glutamine. Cultures were kept at $37^{\circ} \mathrm{C}$ in a humidified atmosphere containing $5 \% \mathrm{CO}_{2}$ until they reached confluence 7 to $14 \mathrm{DIV}$. Confluent cultures were then used as a support for mixed cultures.

\section{Mixed Cortical Cultures}

Mixed cortical cultures containing both neurons and astrocytes were prepared from fetal mice at 14.5 days' gestation. Dissociated cortical cells were plated in 24 wells on a layer of confluent astrocytes, using MS supplemented with $5 \%$ horse serum, $5 \%$ fetal bovine serum, and $2 \mathrm{mmol} / \mathrm{L}$ glutamine. After 7 DIV, nonneuronal cell division was halted by 3 days of exposure to $10 \mathrm{mM}$ Ara-C. Subsequent partial medium replacement was performed twice per week, and after $12 \mathrm{DIV}$, cultures were shifted to a maintenance medium identical to the plating medium but lacking serum, because neurons survive without it. Experiments were performed on cortical cultures after 13 to 14 DIV.

\section{Excitotoxicity}

Slowly triggered excitotoxicity was induced at $37^{\circ} \mathrm{C}$ by 24-hour exposure to $12.5 \mu \mathrm{M} \mathrm{N}$-methyl-D-aspartic acid (NMDA) as an excitotoxin in medium stock supplemented with $10 \mathrm{mM}$ glycine. TXA, EACA, or aprotinin was coapplied at 3 different concentrations (low dose, clinical dose, high dose) with the excitotoxin and left for 24 hours in the bathing medium. The clinical therapeutic concentration of each agent is $0.8 \mathrm{mM}$ for TXA, $1 \mathrm{mM}$ for EACA, ${ }^{8}$ and $250 \mathrm{kIU} / \mathrm{mL}$ for aprotinin. ${ }^{9}$ Low and high dose were one-third and 3 times the clinical dose, respectively. It has been recommended the plasma TXA concentration should be maintained at more than $0.8 \mathrm{mM}$ for patients at high risk of bleeding, ${ }^{10}$ therefore we chose $0.8 \mathrm{mM}$ as the clinical therapeutic concentration of TXA in this study, which corresponds with the recommended dose of TXA $100 \mathrm{mg} / \mathrm{kg}$ as a single bolus before surgery or a medical regimen with a loading dose of $30 \mathrm{mg} / \mathrm{kg}$ plus additional $2 \mathrm{mg} / \mathrm{kg}$ added to the pump prime followed by 16 $\mathrm{mg} / \mathrm{kg} / \mathrm{h}$ infusion in adult patients. ${ }^{10}$

Neuronal death resulting from slowly triggered excitotoxicity was confirmed by examining cultures under phase-contrast microscopy and quantified by measurement of lactate dehydrogenase (LDH) release from damaged cells into the bathing medium 1 day after the onset of excitotoxin exposure. LDH was measured by an enzyme-linked immunosorbent assay kit (Promega, Madison, Wis). The LDH level corresponding to complete neuronal death was determined in sister cultures exposed to $100 \mu \mathrm{M}$ NMDA. Background LDH levels were determined in sister cultures with sham wash as a control and subtracted from experimental values to yield the signal specific to experimentally induced injury.

\section{Serum Deprivation}

Apoptosis was induced by SD for 24 hours at 7 DIV as described previously. ${ }^{4}$ In brief, each cell culture was rinsed; then, aprotinin at tested concentrations was applied to the culture medium without any serum. One group was treated with normal neurobasal medium after the rinse as control, and another was treated with DMEM without any serum and aprotinin. Secondary NMDA receptor activation was blocked by the addition of MK801 to the medium at a final concentration of $10 \mu \mathrm{M}$. Plates were then incubated for 24 hours.

\section{Trypan Blue Staining}

Trypan Blue, a vital stain used to selectively color dead tissue or cells blue, was used to differentiate live neurons from dead neurons. After the induction of apoptosis by $\mathrm{SD}, 100 \mu \mathrm{L}$ of Trypan Blue prewarmed to $37^{\circ} \mathrm{C}$ were added to each well, and the cells were incubated at $37^{\circ} \mathrm{C}$ for 15 minutes. The cells were then fixed in phosphate-buffered formalin solution $(4 \%)$ for 30 minutes at room temperature. Neurons in each dish were counted in 7 different areas using an inverted microscope. Unstained neurons with intact soma and neurites were regarded as viable, and darkstained neurons were considered damaged. Cell counting was performed in a blinded fashion.

\section{3-(4,5-Dimethylthiazol-2-yl)-2,5- Diphenyltetrazolium Bromide Assay}

Viability of neurons was assessed using a 3-(4,5-dimethylthiazol-2-yl)2,5-diphenyltetrazolium bromide (MTT) assay. Briefly, $30 \mu \mathrm{L}$ of MTT were added to each well and incubated at $37^{\circ} \mathrm{C}$ for 3 hours. The supernatant medium was gently removed and cells were solubilized with $250 \mu \mathrm{L}$ of dimethylsulfoxide. Then, $100 \mu \mathrm{L}$ of medium was transferred to a 96-well plate and formazan reduction was detected by measuring absorbance at $570 \mathrm{~nm}\left(\mathrm{OD}_{570}\right)$ with a reference wavelength of $655 \mathrm{~nm}$ in a spectrophotometer.

\section{Hoechst Staining}

The Hoechst stains belong to a family of fluorescent stains that label DNA by fluorescence. Because these fluorescent stains label DNA, they are also commonly used to visualize nuclei and mitochondria. ${ }^{11}$ Briefly, primary cortical neurons that had been treated as mentioned earlier were fixed in $4 \%$ paraformaldehyde for 20 minutes, and were then stained with $20 \mu \mathrm{g} / \mathrm{mL}$ Hoechst 33258 dye for 10 minutes, followed by observation 
using a fluorescence microscope. The dye was excited at $340 \mathrm{~nm}$, and emission was filtered with a 510-nm barrier filter. Neurons with fragmented or condensed DNA or with normal DNA were counted to quantify the apoptotic process. Data are expressed as the ratio of apoptotic neurons to total neurons.

\section{Flow Cytometry}

Neuronal apoptosis was assayed by flow cytometry using an annexin V/fluorescein isothiocyanate (FITC) kit (Molecular Probes, Eugene, Ore), as described previously. ${ }^{12}$ After 24 hours of SD, cells were washed twice with cold phosphate-buffered saline and were detached from the bottom with trypsin-EDTA treatment for 2 to 10 minutes at $37^{\circ} \mathrm{C}$. After adding phosphate-buffered saline with $2 \%$ fetal bovine serum, neurons were harvested and centrifuged at $1500 \mathrm{rpm}$ for 5 minutes. Neurons were resuspended in $1 \times$ binding buffer $(10 \mathrm{mM}$ HEPES, $140 \mathrm{mM} \mathrm{NaCl}$, $2.5 \mathrm{mM} \mathrm{CaCl}_{2}$ ) at a concentration of $1 \times 10^{6}$ cells $/ \mathrm{mL}$. One hundred microliters of each cell suspension was transferred to a $5-\mathrm{mL}$ tube and $5 \mu \mathrm{L}$ of FITC-conjugated annexin $\mathrm{V}$ and propidium iodide (PI) $(50 \mu \mathrm{g} / \mathrm{mL})$ were added. After 15 minutes incubation in the dark at room temperature, $400 \mu \mathrm{L}$ of binding buffer were added to each tube and cells were analyzed for annexin $\mathrm{V}$ binding within 1 hour with a flow cytometer.

\section{Caspase 3/7 and 9 Assays}

Caspase activity was detected using caspase 9 and 3/7 assay kits (Promega, Madison, Wis) as per the manufacturer's protocol. Caspase 3/7 and 9 concentrations were expressed as relative light units (RLU) per milligram of cellular protein measured with a Reporter microplate luminometer (Promega, Madison, Wis). The background luminescence associated with the cell culture and assay reagent (blank reaction) was subtracted from the experimental values. The activities of caspases $3 / 7$ and 9 were reported as the means of experiments conducted in triplicate.

\section{Immunohistochemistry}

To identify caspase 3-positive neural cells after 24 hours SD, cultured neurons were immunolabeled with a primary antibody to caspase3 (Cell Signaling Technology, Danvers, Mass) diluted in $0.1 \mathrm{M}$ phosphatebuffered saline (pH 7.4) containing $0.1 \%$ Triton X-100 and 5\% normal goat serum for 1 hour at $4{ }^{\circ} \mathrm{C}$. Cells were then carefully washed in medium and incubated in the secondary antibody for 1 hour at $4{ }^{\circ} \mathrm{C}$, and mounted on slides. For cell counting, images were captured using a fluorescence microscope. Samples were then analyzed using ImageJ software (available at http://rsbweb.nih.gov/ij/index.html). To determine cell density, the antibody positive cells were quantified in 5 microscopic fields from each sample (6 samples per group) in a blinded fashion.

\section{Statistics}

One-way analysis of variance (ANOVA) with Bonferroni post hoc comparisons was used to detect differences in each analysis between tested groups. Analysis of the data was performed using SPSS version 19.0 (SPSS Inc/IBM, Chicago, Ill).

\section{RESULTS}

Aprotinin, but Not Lysine Analogs, Are Neuroprotective Against Glutamatergic Excitotoxicity

Sham wash and the addition of 2 lysine analogs and aprotinin alone at high dose did not influence neuronal cells in either culture (Figure 1, A-D). Excitotoxicity induced by exposure of the cultures to $12.5 \mu \mathrm{M}$ NMDA for 24 hours resulted in acute swelling of neuronal cell bodies, followed by widespread necrotic neuronal degeneration resulting in disrupted neurons and segmentalized neurites (Figure 1,E). When EACA and TXA were coapplied in the medium with the excitotoxin, both lysine analogs did not preserve neuronal cells and neurites (Figure 1, $F$ and $G$ ). On the other hand, the damage was significantly reduced under the condition with aprotinin (Figure $1, H$ ). Exposure to $12.5 \mathrm{mM}$ NMDA caused approximately $70 \%$ neuronal cell death (Figure 1,I). There were no effects on cell death with any dose of TXA or EACA (Figure 1,I). In contrast, aprotinin reduced neuronal death in a dose-dependent fashion (Figure 1,I). Compared with NMDA alone, no significant changes in cell death were observed for clinical doses of TXA or EACA, whereas aprotinin significantly reduced cell death by $-31 \%$ on average (Figure $1, J$ ). The results indicate that, among major antifibrinolytic agents used clinically in cardiac surgery, only aprotinin has a neuroprotective effect against excitotoxic brain injury.

\section{Aprotinin Prevents SD-Induced Apoptosis in Cortical Neurons}

In addition to the effect of aprotinin against glutamatergic excitotoxicity, our previous results suggested a potential antiapoptotic effect. ${ }^{13}$ In the present study using primary cortical neuronal cultures, 100 and $200 \mathrm{kIU} / \mathrm{mL}$ aprotinin significantly decreased the percentage of cells positive with Trypan Blue resulting from SD-induced apoptosis, ${ }^{4,14}$ compared with the control (Figure 2, A). Consistent with these results, cell viability using the MTT assay significantly decreased at 24 hours after SD in the no aprotinin group; $100 \mathrm{kIU} / \mathrm{mL}$ and $200 \mathrm{kIU} / \mathrm{mL}$ aprotinin significantly increased the viability compared with no aprotinin (Figure 2, B). When Hoechst 33258 staining was performed at the same time point and damaged cells were characterized by condensed chromatin, reduced nuclear size, and nuclear fragmentation (Figure 2, $C-G)$, it was identified that the percentage of damaged cells significantly decreased in 100 and $200 \mathrm{kIU} / \mathrm{mL}$ aprotinin $(25.0 \% \pm 3.8 \%$ and $20.3 \% \pm 3.6 \%$, respectively $)$ compared with no aprotinin $(34.0 \% \pm 4.7 \% ; P<.01)$. However, there were no significant differences between $50 \mathrm{kIU} /$ $\mathrm{mL}$ and no aprotinin in assessments using Trypan Blue, MTT, and Hoechst 33258 (Figure 2, $A, B$, and $E$ ). The percentage of early apoptotic neurons identified by annexin $\mathrm{V}^{+}$using flow cytometry was not significantly different between aprotinin and no aprotinin treatment after 24 hours SD. When advanced apoptosis was indicated by annexin $\mathrm{V}^{+}$and $\mathrm{V} / \mathrm{PI}^{+}, 78.8 \%$ of neurons $( \pm 10.4 \%)$ were identified as having undergone advanced apoptosis; this effect was significantly reduced by aprotinin at all 3 concentrations tested $(50 \mathrm{kIU} / \mathrm{mL}$ aprotinin, $46.1 \% \pm 12.0 \% ; 100 \mathrm{kIU} /$ $\mathrm{mL}, 37.1 \% \pm 14.3 \% ; 200 \mathrm{kIU} / \mathrm{mL}, 43.5 \% \pm 21.3 \%$; $P<.01)$. These findings demonstrate that, in addition to a neuroprotective effect against excitotoxicity, aprotinin significantly inhibits apoptosis in cortical neurons. 

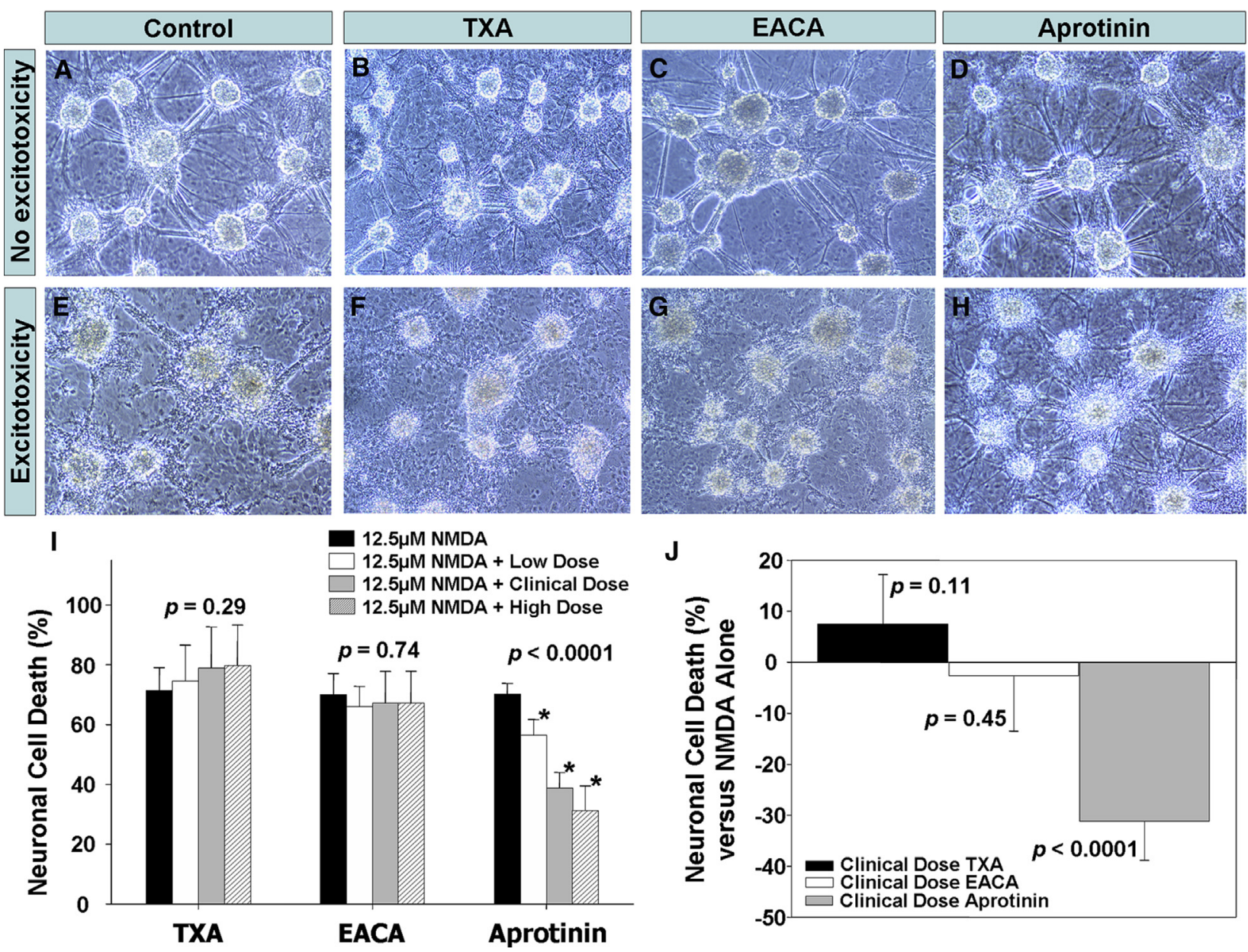

FIGURE 1. Aprotinin, but not lysine analogs, are neuroprotective against glutamatergic excitotoxicity. A-D, Mixed cortical culture at 24 hours after Sham wash (A), and Sham wash with clinical dose TXA (B) EACA (C) and aprotinin (D). E-H, Mixed cortical culture after 24-hour exposure with 12.5 $\mu$ M NMDA (E), and $12.5 \mu \mathrm{M}$ NMDA with clinical dose TXA (F) EACA (G) and aprotinin (H). I, Percentage of cell death at 24 hours after $12.5 \mu \mathrm{M}$ NMDA exposure with TXA, EACA, and aprotinin. Neural cell death was identified by LDH assay measuring LDH levels in bathing medium in cultures. ${ }^{4}$ Low, clinical, and high doses of aprotinin reduced neuronal death from $70 \%$ to $56 \%, 39 \%$, and $31 \%$, respectively $(\mathrm{F}=104.6, P<.0001)$. J, Percentage cell death at 24 hours after $12.5 \mu \mathrm{M}$ NMDA exposure with clinical doses of TXA, EACA, and aprotinin compared with $12.5 \mu \mathrm{M}$ NMDA alone. There were no significant changes in TXA $(+8 \%, P=.11)$ and EACA $(-3 \%, P=.45)$. A clinical dose of aprotinin significantly reduced cell death by $-31 \%$ on average $(P<.0001) . * P<.001$ versus $12.5 \mu \mathrm{M}$ NMDA by ANOVA with Bonferroni comparisons. Data are shown as means \pm standard error of the mean $(\mathrm{n}=12)$. $N M D A, N$-Methyl-D-aspartic acid; EACA, $\varepsilon$-aminocaproic acid; TXA, tranexamic acid.

\section{Aprotinin Inhibits Apoptosis Via a Mitochondrial Pathway and $250 \mathrm{kIU} / \mathrm{mL}$ is an Optimal Dose for Protection}

To identify a pathway involving aprotinin-induced inhibition of apoptosis, caspase 3/7 and 9 levels were assessed after 24 hours SD. Aprotinin significantly decreased the level of caspase $3 / 7$ in a dose-dependent manner (Figure 3, A). This dose-dependent change correlated with apoptotic neural injury identified by Trypan Blue and MTT assays (Figure 2, $A$ and $B$ ), suggesting that a caspase-dependent mechanism includes an antiapoptotic effect due to aprotinin. It was also identified that caspase 9 activity was significantly inhibited by 100 and 200 $\mathrm{kIU} / \mathrm{mL}$ aprotinin (Figure 3, B). When apoptosis was induced by $200 \mathrm{nM}$ staurosporin, however, there were no significant differences in the MTT assay between any doses of aprotinin (data not shown). It is known that staurosporin induces apoptosis through both caspase-dependent and -independent mechanisms ${ }^{15}$; SD induces apoptotic cell death using a caspase-dependent mechanism via a mitochondrial pathway. ${ }^{16}$ Therefore, it is likely that inhibition of apoptosis by aprotinin occurs by a caspase-dependent mechanism through the mitochondrial pathway.

The antiapoptotic effect of aprotinin was assessed from $100 \mathrm{kIU} / \mathrm{mL}$ up to $1000 \mathrm{kIU} / \mathrm{mL}$ to identify the optimal dose for adjunctive neuroprotection. Using immunohistochemistry, 100 and $250 \mathrm{kIU} / \mathrm{mL}$ aprotinin dosedependently decreased caspase $3^{+}$cell percentages after 

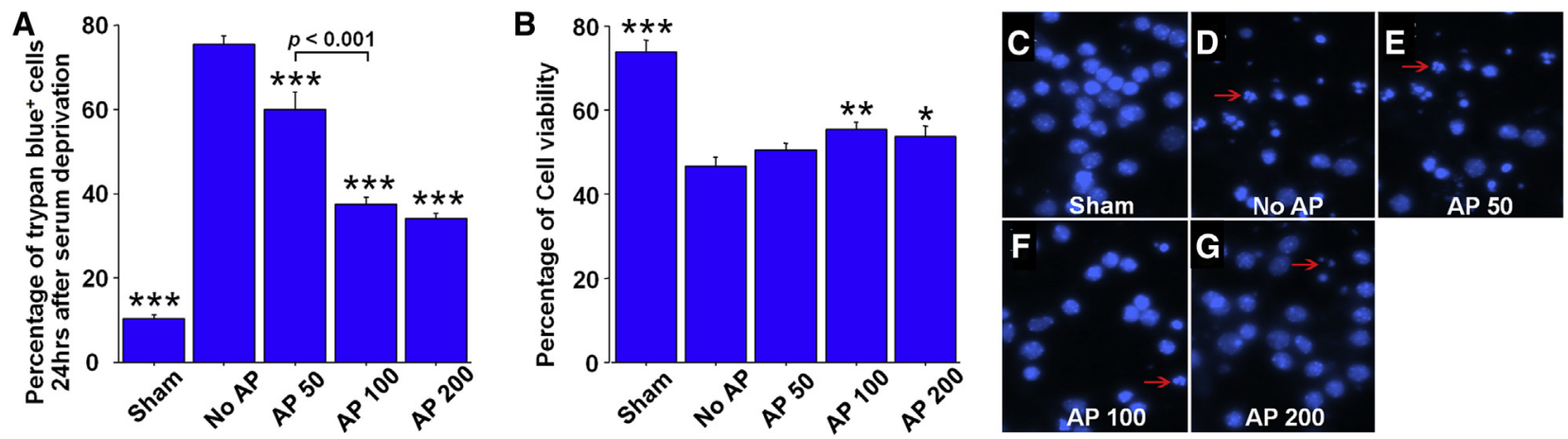

FIGURE 2. Aprotinin prevents serum deprivation (SD)-induced apoptosis in cortical neurons. A, Percentage of Trypan Blue positive cells at 24 hours after SD. Ten percent cell death in the control supports a technical consistency in our study. ${ }^{35}$ Aprotinin at 50, 100 and $200 \mathrm{kIU} / \mathrm{mL}$ decreased the percentage of Trypan Blue positive cells from $75 \%$ to $60 \%, 37 \%$ and $34 \%$, respectively. B, Cell viability using the MTT assay after 24 hours SD. Aprotinin at 100 and 200 $\mathrm{kIU} / \mathrm{mL}$ significantly increased the viability compared with no aprotinin $(P<.05)$. There was no significant difference between no aprotinin and $50 \mathrm{kIU} / \mathrm{mL}$ aprotinin. C-G, Images with Hoechst 33258 staining at 24 hours after sham wash (C) and after SD with aprotinin at the concentration of 0 (D), 50 (E), 100 $(\mathrm{F})$, and $250 \mathrm{kIU} / \mathrm{mL}(\mathrm{G}) . * P<.05, * * P<.01, * * * P<.001$ versus aprotinin $0 \mathrm{kIU} / \mathrm{mL}$ by ANOVA with Bonferroni comparisons. Data are shown as means \pm standard error of the mean $(\mathrm{n}=8)$. $A P$, Aprotinin.

24 hours SD (Figure 3, $C-F$ ). Aprotinin at a concentration of 500 and $1000 \mathrm{kIU} / \mathrm{mL}$ also reduced the percentage compared with no aprotinin; however, these doses did not provide significant reduction compared with $250 \mathrm{kIU} / \mathrm{mL}$ (Figure 3,C). This suggests that approximately 200 to $250 \mathrm{kIU} / \mathrm{mL}$ is an optimal dose of aprotinin for adjunctive protection during cardiac surgery.

\section{DISCUSSION}

This study is the first to describe the neuroprotective potential of 3 antifibrinolytic agents used during cardiac surgery against glutamatergic excitotoxicity in mixed cortical cell culture models. The antiapoptotic effects of aprotinin were demonstrated using various analyses in a primary neuronal cell culture system. The optimal dose for neuroprotection in clinical applications during cardiac surgery was identified.

Recently, there has been increasing interest in the role of antifibrinolytic agents in postoperative neurologic events. High-dose TXA has been identified as an independent predictor of early seizures after cardiopulmonary bipass in clinical studies. ${ }^{17,18}$ A retrospective data analysis has also demonstrated that even moderate doses of TXA are associated with double the rate of convulsive seizures and in-hospital mortality. ${ }^{19}$ Consistent with these findings, a preclinical study by Lecker and colleagues ${ }^{20}$ identified that the reduction in function of glycine receptors caused by TXA leads to disinhibition and proconvulsive effects. Because their results and those of others ${ }^{21}$ determined that TXA is a competitive antagonist of $\gamma$-aminobutyric acid type $A\left(\mathrm{GABA}_{\mathrm{A}}\right)$ receptors, it is suggested that TXA inhibition of $\mathrm{GABA}_{\mathrm{A}}$ receptors increases network excitability. ${ }^{20}$ EACA is also a competitive antagonist of glycine receptors, but not aprotinin. ${ }^{20}$ The present study investigated the neuroprotective potential of antifibrinolytic agents against glutamatergic excitotoxicity, which is a major mechanism of ischemic neuronal cell death. An in vitro culture model was used, but electrophysiologic activity was not studied. However, an ex vivo rodent brain slice model has recently been developed replicating specific brain conditions of deep hypothermic circulatory arrest including ischemia-reperfusion/reoxygenation under hypothermia. ${ }^{22}$ Receptor expression and function on neurons and glial cells are dynamically changing during development ${ }^{23}$; however, there is little information regarding the effects of pharmacologic reagents including antifibrinolytics during cardiac surgery on electrophysiologic activity in the developing brain. Rodent brain slice models have been used extensively for electrophysiologic studies and for the development of pharmacologic therapy. Thus, the model will be useful for the study of optimal antifibrinolytic agents in pediatric cardiac surgery. Future studies using the in vitro neuronal cell culture model, ex vivo brain slice model, and in vivo large animal model will provide novel insights regarding cellular and molecular mechanisms underlying neurologic deficits after cardiac surgery, and allow for the design of targeted therapies and conditions that will minimize the risk of neurodevelopmental deficits in patients with congenital heart disease.

In 2007, the US Food and Drug Administration suggested to the Bayer Corporation that it should suspend marketing of aprotinin following a retrospective propensity match review by Mangano and colleagues ${ }^{24}$ and preliminary analysis of a prospective trial in Canada (BART trial). ${ }^{25}$ The Bayer Corporation responded by voluntarily removing all remaining stocks of aprotinin from the US market in 2008. ${ }^{25}$ However, evidence has been accumulating on the deleterious effects of alternative hemostatic agents such as Factor VII and lysine analogs as well as the disadvantages of massive transfusion, suggesting that the protective effects 

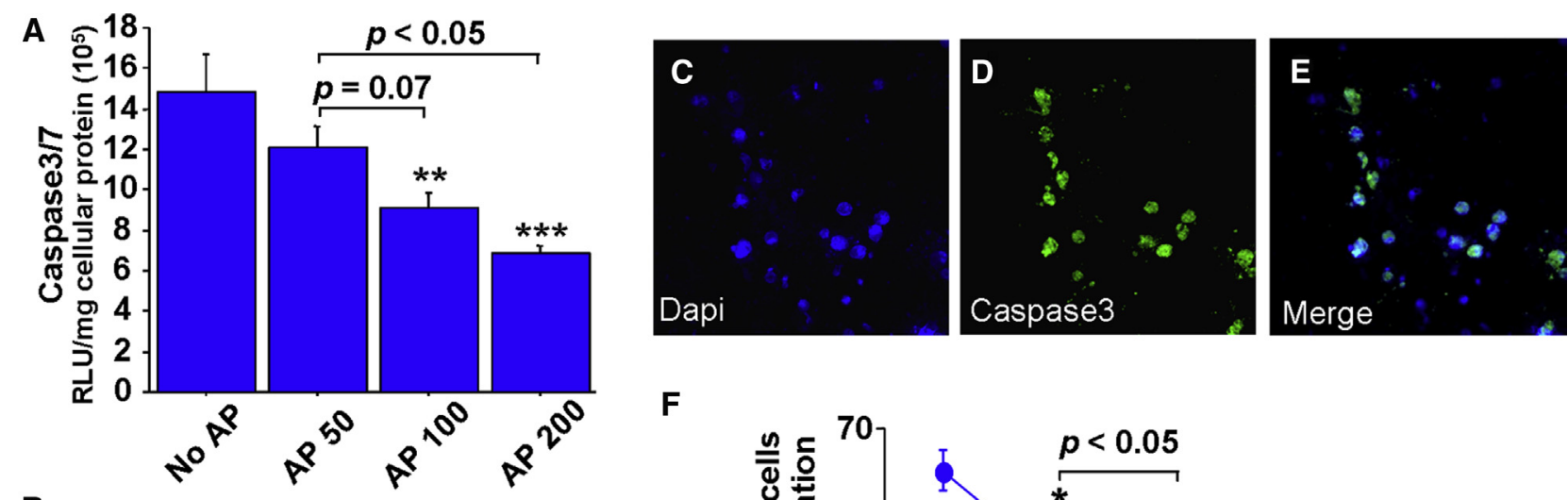

$\mathbf{F}$
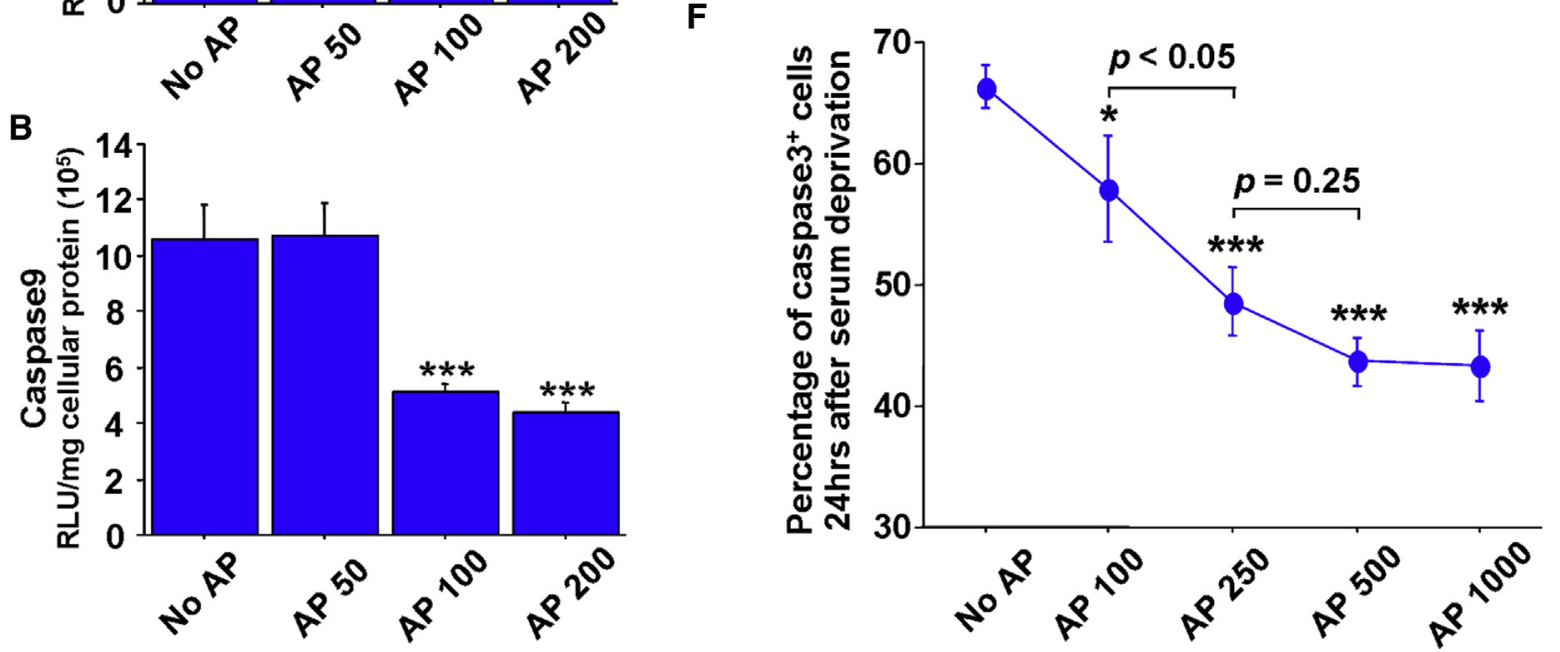

FIGURE 3. Aprotinin inhibits apoptosis via the mitochondrial pathway and $250 \mathrm{kIU} / \mathrm{mL}$ is an optimal dose for protection. A and B, Caspase $3 / 7$ and 9 activity after 24 hours serum deprivation (SD) in primary cortical neuron culture. C-E, Images after 24 hours SD in a neuron culture without aprotinin. F, Percentage of caspase 3-positive cells at 24 hours after SD with aprotinin at the concentration of $0,100,250,500$, and $1000 \mathrm{kIU} / \mathrm{mL}$. $* P<.05$, $* * P<.01, * * * P<.001$ versus aprotinin $0 \mathrm{kIU} / \mathrm{mL}$ by ANOVA with Bonferroni comparisons. Data are shown as means \pm standard error of the mean $(\mathrm{n}=6-8) . A P$, Aprotinin.

of aprotinin outweighed the risks involved. ${ }^{26-28}$ Based on subsequent analysis of the BART trial, Health Canada concluded in 2011 that the trial could not be reliably used to assess the benefit-risk balance of aprotinin as a result of study weaknesses. ${ }^{29}$ The European Medicines Agency also released a statement in 2012 indicating that the benefits of aprotinin outweigh its risks in patients and recommended to the European Union that the suspension of the license for aprotinin in this context be lifted. ${ }^{29}$

In addition to functioning as an important hemostatic agent, it has been suggested that aprotinin inhibits nitric oxide synthase activity ${ }^{30}$ and the proinflammatory activation of endothelial cells. ${ }^{31}$ Using both a piglet model involving cardiopulmonary bypass as well as a neuronal cell culture model, abundant evidence for the neuroprotective effects of aprotinin is available. ${ }^{5,6,32-34}$ Thus, it can be inferred that aprotinin is the preferred antifibrinolytic agent during cardiac surgery, in particular for patients at high risk of procedure-related brain injury, such as those undergoing circulatory arrest. It is likely that aprotinin will be reintroduced into the United States through a distributor other than the Bayer Corporation. This will allow clinical trials to explore the neuroprotective effects of aprotinin as studied in this report.

\section{CONCLUSIONS}

Aprotinin at 200 to $250 \mathrm{kIU} / \mathrm{mL}$ exerts maximal protective effects on primary cortical neurons cultured in vitro. This effect might result from caspase-dependent and/or -independent pathways. In conjunction with our previous studies, aprotinin is a multipotent serine protease inhibitor that can protect the brain during cardiac surgery.

The authors thank Dr David Zurakowski for assistance with statistical analysis. The authors are thankful to Dr Olivier Nicole for assistance in the preparation of the cell culture model.

\section{References}

1. Johnston MV, Fatemi A, Wilson MA, Northington F. Treatment advances in neonatal neuroprotection and neurointensive care. Lancet Neurol. 2011;10: 372-82.

2. Silverstein FS, Buchanan K, Johnston MV. Perinatal hypoxia-ischemia disrupts striatal high-affinity [3H]glutamate uptake into synaptosomes. J Neurochem. 1986;47:1614-9. 
3. Tsirka SE, Gualandris A, Amaral DG, Strickland S. Excitotoxin-induced neuronal degeneration and seizure are mediated by tissue plasminogen activator. Nature. 1995;377:340-4.

4. Nicole O, Docagne F, Ali C, Margaill I, Carmeliet P, MacKenzie ET, et al. The proteolytic activity of tissue-plasminogen activator enhances nmda receptormediated signaling. Nat Med. 2001;7:59-64.

5. Iwata Y, Nicole O, Okamura T, Zurakowski D, Jonas RA. Aprotinin confers neuroprotection by reducing excitotoxic cell death. J Thorac Cardiovasc Surg. 2008; 135:573-8.

6. Anttila V, Hagino I, Iwata Y, Mettler BA, Lidov HG, Zurakowski D, et al. Aprotinin improves cerebral protection: evidence from a survival porcine model. J Thorac Cardiovasc Surg. 2006;132:948-53.

7. Mannucci PM, Levi M. Prevention and treatment of major blood loss. N Engl J Med. 2007;356:2301-11.

8. Nielsen VG, Cankovic L, Steenwyk BL. Epsilon-aminocaproic acid inhibition of fibrinolysis in vitro: should the 'therapeutic' concentration be reconsidered? Blood Coagul Fibrinolysis. 2007;18:35-9.

9. Mannucci PM. Hemostatic drugs. N Engl J Med. 1998;339:245-53.

10. Dowd NP, Karski JM, Cheng DC, Carroll JA, Lin Y, James RL, et al. Pharmacokinetics of tranexamic acid during cardiopulmonary bypass. Anesthesiology. 2002; $97: 390-9$

11. Tucker LM, Morton AJ. A simple method for quantifying changes in neuronal populations in primary cultures of dissociated rat brain. J Neurosci Methods. 1995;59:217-23.

12. Li S, Zhang Z, Xue J, Liu A, Zhang H. Cold-inducible rna binding protein inhibits $\mathrm{H}(2) \mathrm{O}(2)$-induced apoptosis in rat cortical neurons. Brain Res. 2012; 1441:47-52.

13. Iwata Y, Nicole O, Okamura T, Zurakowski D, Jonas RA. Aprotinin confers neuroprotection by reducing apoptotic cell death. Asian Cardiovasc Thorac Ann. 2010;18:170-3.

14. Kulkarni GV, McCulloch CA. Serum deprivation induces apoptotic cell death in a subset of Balb/c 3T3 fibroblasts. J Cell Sci. 1994;107(Pt 5):1169-79.

15. Belmokhtar CA, Hillion J, Segal-Bendirdjian E. Staurosporine induces apoptosis through both caspase-dependent and caspase-independent mechanisms. Oncogene. 2001;20:3354-62.

16. Charles I, Khalyfa A, Kumar DM, Krishnamoorthy RR, Roque RS, Cooper N, et al. Serum deprivation induces apoptotic cell death of transformed rat retinal ganglion cells via mitochondrial signaling pathways. Invest Ophthalmol Vis Sci. 2005;46:1330-8.

17. Kalavrouziotis D, Voisine P, Mohammadi S, Dionne S, Dagenais F. High-dose tranexamic acid is an independent predictor of early seizure after cardiopulmonary bypass. Ann Thorac Surg. 2012;93:148-54.

18. Keyl C, Uhl R, Beyersdorf F, Stampf S, Lehane C, Wiesenack C, et al. High-dose tranexamic acid is related to increased risk of generalized seizures after aortic valve replacement. Eur J Cardiothorac Surg. 2011;39:e114-21.

19. Koster A, Borgermann J, Zittermann A, Lueth JU, Gillis-Januszewski T, Schirmer U. Moderate dosage of tranexamic acid during cardiac surgery with cardiopulmonary bypass and convulsive seizures: incidence and clinical outcome. Br J Anaesth. 2013;110:34-40.

20. Lecker I, Wang DS, Romaschin AD, Peterson M, Mazer CD, Orser BA. Tranexamic acid concentrations associated with human seizures inhibit glycine receptors J Clin Invest. 2012;122:4654-66.

21. Furtmuller R, Schlag MG, Berger M, Hopf R, Huck S, Sieghart W, et al. Tranexamic acid, a widely used antifibrinolytic agent, causes convulsions by a gammaaminobutyric acid(a) receptor antagonistic effect. J Pharmacol Exp Ther. 2002;301:168-73.

22. Murata A, Agematsu K, Korotcova L, Gallo V, Jonas RA, Ishibashi N. Roden brain slice model for the study of white matter injury. J Thorac Cardiovasc Surg. 2013;146:1526-33.

23. McLean C, Ferriero D. Mechanisms of hypoxic-ischemic injury in the term in fant. Semin Perinatol. 2004;28:425-32.

24. Mangano DT, Tudor IC, Dietzel C. The risk associated with aprotinin in cardiac surgery. N Engl J Med. 2006;354:353-65.

25. Jonas RA. Aprotinin and pediatric heart surgery: children are not small adults Journal of Generic Medicines. 2011;8:76-80.

26. Karkouti K, Wijeysundera DN, Yau TM, McCluskey SA, Tait G, Beattie WS. The risk-benefit profile of aprotinin versus tranexamic acid in cardiac surgery. Anesth Analg. 2010;110:21-9.

27. Ferraris VA. Facts, opinions, and conclusions: aprotinin brings out all of these. J Thorac Cardiovasc Surg. 2013;145:240-2.

28. Pasquali SK, Li JS, He X, Jacobs ML, O’Brien SM, Hall M, et al. Comparative analysis of antifibrinolytic medications in pediatric heart surgery. J Thorac Cardiovasc Surg. 2012;143:550-7.

29. McMullan V, Alston RP III. Aprotinin and cardiac surgery: a sorry tale of evidence misused. Br J Anaesth. 2013;110:675-8.

30. Venturini G, Colasanti M, Ascenzi P. Aprotinin, the first competitive protein inhibitor of nos activity. Biochem Biophys Res Commun. 1998;249:263-5.

31. Day JR, Taylor KM, Lidington EA, Mason JC, Haskard DO, Randi AM, et al Aprotinin inhibits proinflammatory activation of endothelial cells by thrombin through the protease-activated receptor 1. J Thorac Cardiovasc Surg. 2006; 131:21-7.

32. Iwata Y, Okamura T, Ishibashi N, Zurakowski D, Lidov HG, Jonas RA. Optimal dose of aprotinin for neuroprotection and renal function in a piglet survival model. J Thorac Cardiovasc Surg. 2009;137:1521-9.

33. Aoki M, Jonas RA, Nomura F, Stromski ME, Tsuji MK, Hickey PR, et al. Effects of aprotinin on acute recovery of cerebral metabolism in piglets after hypothermic circulatory arrest. Ann Thorac Surg. 1994;58:146-53.

34. Ishibashi N, Iwata Y, Zurakowski D, Lidov H, Jonas RA. Aprotinin protects the cerebral microcirculation during cardiopulmonary bypass. Perfusion. 2009;24: 99-105.

35. Ratan RR, Lee PJ, Baraban JM. Serum deprivation inhibits glutathione depletion-induced death in embryonic cortical neurons: evidence against oxidative stress as a final common mediator of neuronal apoptosis. Neurochem Int. 1996;29:153-7. 